\title{
Characterization of a Segregation Distortion Locus with Powdery Mildew Resistance in a Wheat-Thinopyrum intermedium Introgression Line WE99
}

Pengtao Ma, Hongxing Xu, Guohao Han, Qiaoling Luo, Yunfeng Xu, Xiaotian Zhang, and Diaoguo An, Center for Agricultural Resources Research, Institute of Genetics and Developmental Biology, Chinese Academy of Sciences, Shijiazhuang 050021, China; Lihui Li, The National Key Facility for Crop Gene Resources and Genetic Improvement, Institute of Crop Science, Chinese Academy of Agricultural Sciences, Beijing 100081; and Yu Sun, Institute of Crop Genetics, Shanxi Academy of Agricultural Science, Taiyuan 030031, China

\begin{abstract}
Ma, P. T., Xu, H. X., Li, L. H., Han, G. H., Luo, Q. L., Sun, Y., Xu, Y. F., Zhang, X. T., and An, D. G. 2016. Characterization of a segregation distortion locus with powdery mildew resistance in a wheat-Thinopyrum intermedium introgression line. Plant Dis. 100:1541-1547.

Exploitation of host resistance is important for controlling powdery mildew of wheat (Triticum aestivum L.). In this study, a wheat-Thinopyrum intermedium introgression line, designated WE99, conferred seedling resistance to 47 of 49 Blumeria graminis $\mathrm{f}$. sp. tritici isolates. Genetic analysis demonstrated that the resistance segregation deviated significantly from a single gene Mendelian ratio. However, marker analysis indicated that only a single recessive resistance gene, temporarily designated PmWE99, conferred powdery mildew resistance (Pm). PmWE99 was mapped to chromosome arm $2 \mathrm{BS}$ and linked to the three simplesequence repeat markers Gwm148, Gwm271, and Barc55. Using race

spectrum analysis, $P m W E 99$ was shown to be significantly different from the documented genes Pm42 and MlIW170 located on chromosome arm $2 \mathrm{BS}$ and, thus, appeared to be a new Pm gene. Examination of the genotype frequencies in the $\mathrm{F}_{2: 3}$ families showed that a genetic variation in the PmWE99 interval that favored the transmission of the WE99 allele could be the cause of the deviated segregation. Further investigation revealed that the abnormal segregation only occurred at the PmWE99 interval and was not common at other loci in this population. Identification of PmWE99 will increase the diversity of the Pm genes for wheat improvement.
\end{abstract}

Wheat powdery mildew, caused by Blumeria graminis f. sp. tritici $(B g t)$, is a devastating disease, which can cause severe yield losses in a relatively short time (Morgounov et al. 2012). Chemical protection, specific agronomic management practices, and the breeding of resistant cultivars were several solutions that had been used to prevent epidemics of this disease (Hardwick et al. 1994; Horst 2013; Sharma et al. 2004). Undoubtedly, host resistance is the most effective, economical, and environmentally sound and consistently used method (Petersen et al. 2014).

Up to now, more than 70 formally designated powdery mildew resistance $(\mathrm{Pm})$ genes or alleles $(\mathrm{Pm} 1$ to $\mathrm{Pm} 54)$ and 20 temporarily designated $P m$ genes have been identified at 49 loci distributed on all the chromosomes except chromosome 3D in common wheat and its relatives (Ma et al. 2015a,b; McIntosh et al. 2014). An increasing number of studies showed the diversity in powdery mildew resistance. Most $P m$ genes displayed dominant inheritance; however, a dozen $P m$ genes confer recessive resistance, such as the $P m 5$ alleles (Pm5a to Pm5e) (Hsam et al. 2001; Huang et al. 2003), Pm9 (Schneider et al. 1991), Pm26 (Rong et al. 2000), Pm42 (Hua et al. 2009), and several temporarily designated $P m$ genes (Sun et al. 2006; Xu et al. 2008). Qualitative resistance is common in documented $\mathrm{Pm}$ genes; in contrast, several of them are quantitatively inherited, such as Pm38 (Spielmeyer et al. 2008), Pm39 (Lillemo et al. 2008), Pm46 (Herrera-Foessel et al. 2014) Pm54 (Hao et al. 2015), and others. Most qualitative resistance for powdery mildew followed Mendel's law of segregation; however, a few segregated abnormally, such as $P m X$ (Fu et al. 2013) and two stem rust resistance genes, $\operatorname{Sr} 36$ (Tsilo et al. 2008) and $\operatorname{Sr} 40$ (Wu et al. 2009).

\section{Corresponding author: D. An; E-mail: dgan@ @jziam.ac.cn}

*The $\boldsymbol{e}$-Xtra logo stands for "electronic extra" and indicates that one supplementary figure and one supplementary table are published online.

Accepted for publication 28 March 2016.

http://dx.doi.org/10.1094/PDIS-11-15-1352-RE

(C) 2016 The American Phytopathological Society
Although numerous $P m$ genes have been identified, most of them are race specific and liable to the breakdown of resistance once they become widely deployed in wheat cultivars (Chen 2005; Xiao et al. 2013). Identification and utilization of new $P m$ genes from various wheat germplasm resources is a continuous challenge. In the past, the discovery of novel resistance sources mainly focused on cultivated wheat (McIntosh et al. 2014). However, high genetic homogeneity within the cultivated species creates unprecedented challenges to wheat breeding (Gupta et al. 2010; Karsai et al. 2012; Khan et al. 2011). Transfer of resistance genes from wheat relatives is an important strategy for resistance breeding. In fact, wheat relatives have been used as genetic resources for the introgression of powdery mildew resistance into the wheat genome, such as the genes $P m 40$ and Pm43 from Thinopyrum intermedium (He et al. 2009; Luo et al. 2009); Pm21 from Haynaldia villosa (Chen et al. 1995); Pm7, Pm8, Pm17, and Pm20 from Secale cereale (Friebe et al. 1994, 1996; Heun et al. 1990; Hsam and Zeller 1997), Pm26 and Pm42 from Triticum turgidum var. dicoccoides (Hua et al. 2009; Rong et al. 2000); and Ml5253 from T. turgidum subsp. dicoccum (Piarulli et al. 2012).

In this study, a wheat distant hybridization descendant crossed by common wheat and Thinopyrum intermedium, designated WE99, showed powdery mildew resistance at both seedling and adult stages. The objectives of the present study were to (i) detect $T$. intermedium chromatin in WE99 and confirm its chromosome composition, (ii) analyze the inheritance of its seedling resistance to powdery mildew, (iii) determine the chromosomal location of the resistance genes using molecular markers, and (iv) compare its reaction pattern with other documented $P m$ genes using resistance spectrum analysis.

\section{Materials and Methods}

Plant materials. Wheat line WE99 was derived from a cross between common wheat and T. intermedium (the pedigree is shown in Supplementary Figure S1). 'Huixianhong' wheat served as susceptible parent in a cross with WE99 to produce $F_{1}$ hybrids, $F_{2}$ populations, and $\mathrm{F}_{2: 3}$ families for genetic analysis and molecular mapping of resistance genes. Common wheat lines $2 \mathrm{H} 7165$ (with Pm42) and P170 (with MlIW170) were derived from the documented Pm42 and MlIW170 donor wild emmer accessions G-303-1M and 
P170, respectively, and kindly provided by Professor Zhiyong Liu (China Agricultural University, Beijing). They were used in the comparisons of their $P m$ genes with that of WE99. Huixianhong was used as the susceptible check.

Molecular cytological detection of $T$. intermedium chromatin in WE99. Genomic in situ hybridization (GISH) analysis was conducted for detection of T. intermedium chromatin in WE99 and to determine its chromosomal composition. To confirm the genetic stability, WE99 was examined during five consecutive wheat growing seasons. Each year, five plants were examined and five root tip cells were analyzed per plant. The mitotic chromosomes of root tips cells of WE99 were prepared and observed following the method of Han et al. (2006). Total genomic DNA of T. intermedium was extracted (Sharp et al. 1988) and used as a probe after labeling with fluorescein-12-dUTP by the nick translation method (Han et al. 2007). Detection and visualization of the chromosomes were performed as described by Han et al. (2009). The cells were captured by a DVC CCD digital camera, and program Image Pro Plus 4.0 was used for merging each color channel from the captured images.

In order to identify the $T$. intermedium chromatin in WE99 and its relationship to the powdery mildew resistance genes, 20 simplesequence repeat (SSR) markers that produce specific bands from the T. intermedium genome (Liu et al. 2013) were used to amplify WE99, T. intermedium, Huixianhong, 'Chinese Spring', and several homozygous resistant and susceptible $\mathrm{F}_{2: 3}$ families from the cross of Huixianhong to WE99.

Disease assessment. At the adult stage, WE99 was evaluated for its adult resistance to a mixture of $B g t$ isolates collected from northern China in five consecutive wheat growing seasons. At the one-leaf stage, seedlings were inoculated with fresh spores using the dusting method (An et al. 2013). They were then transferred to a greenhouse where the environment was maintained at high humidity and $18^{\circ} \mathrm{C}$ (day) to $12^{\circ} \mathrm{C}$ (night), with a photoperiod of 12 to $14 \mathrm{~h}$ of light per day. Infection types (IT) were scored 14 to 15 days after inoculation when pustules were fully developed on susceptible controls 'Mingxian 169' and Huixianhong. The IT of each plant was recorded on a 0 -to- 4 scale, in which the plants with IT 0 to 2 were classified as a resistant and IT 3 to 4 as susceptible phenotypes for powdery mildew (Si et al. 1992).

Line WE99 was tested for its reactions to 49 single-pustulederived $B g t$ isolates by separate artificial inoculation in a temperaturecontrolled greenhouse (Supplementary Table S1). Wheat lines 2H7165 and P170, several resistant commercial cultivars that are currently popular in China (i.e., 'Jimai 22', 'Liangxing 66', 'Liangxing 99', and 'Wennong 14'), the susceptible parent Huixianhong, and the susceptible control Mingxian 169 were also included in the tests. Each isolate was placed in an independent and enclosed space to avoid cross-infection between different isolates. Each test was repeated three times, and five plants were included in each test. Meanwhile, 40 plants of each $\mathrm{F}_{2: 3}$ family of Huixianhong and WE99 were inoculated with isolate B03 and the IT of each plant was scored for genetic and molecular marker analysis.

Molecular marker analysis. Equal amounts of genomic DNA from 10 resistant (with IT 0) and 10 susceptible (with IT 4) $F_{2}$ plants were extracted from fresh leaves after disease assessment of the $F_{2}$ population (Sharp et al. 1988). They were bulked to produce resistant and susceptible pools for bulked segregant analysis (BSA). In total, about 400 SSR markers distributed on all 21 wheat chromosomes were tested for polymorphisms between the parents and bulks. Then, $\mathrm{F}_{2}$ population were transplanted in the field to harvest $\mathrm{F}_{2: 3}$ families. Genomic DNA of each $\mathrm{F}_{2: 3}$ family was extracted from fresh leaves after disease assessment (Sharp et al. 1988). Markers showing polymorphisms between the parents and bulks were used to genotype all $184 \mathrm{~F}_{2: 3}$ families. The procedures for polymerase chain reaction (PCR), separation, and visualization of the PCR products followed the method of Xu et al. (2012), and the PCR profile was modified as follows: 1 cycle at $94^{\circ} \mathrm{C}$ for $3 \mathrm{~min}$; followed by 35 cycles at $94^{\circ} \mathrm{C}$ for $30 \mathrm{~s}, 50$ to $60^{\circ} \mathrm{C}$ (depending on the specific primer) for $40 \mathrm{~s}$, and $72^{\circ} \mathrm{C}$ for $40 \mathrm{~s}$; and a final extension at $72^{\circ} \mathrm{C}$ for $5 \mathrm{~min}$.

Map construction. Goodness-of-fit of segregation data with hypothesized 3:1 and 1:2:1 ratios for $F_{2}$ population and $F_{2: 3}$ families were evaluated with $\chi^{2}$ tests using Sigmaplot 2001 software (SPSS Inc., Chicago). Linkage maps with genetic distances between markers and the resistance gene were prepared using Software MAPMAKER 3.0 with a $\log$ of the likelihood threshold of 3.0 (Lincoln et al. 1992) using a total of $184 \mathrm{~F}_{2.3}$ families from the cross of Huixianhong to WE99. Recombination fractions were converted to map distances (in centimorgans) using the Kosambi mapping function (Kosambi 1943).

\section{Results}

Detection of the $T$. intermedium chromatin in WE99. Wheat line WE99 was selected from distant hybridization progenies from a cross of common wheat and T. intermedium. GISH analysis using T. intermedium genomic DNA as a probe was first used to detect T. intermedium chromatin and determine the chromosome constitution of WE99. The result revealed that WE99 had 42 chromosomes at the mitotic metaphase as common wheat (Fig. 1). These chromosomes showed only blue signals when counterstained with 4,6diamidino-2-phenylindole and no bright-green hybridization signals were detected, indicating that there were cytologically undetectable $T$. intermedium chromatin segments on the wheat chromosomes. Therefore, no $T$. intermedium chromosome segments were detected cytologically in WE99.

In order to further confirm these results, 20 molecular markers that produce specific bands from the T. intermedium genome (Liu et al. 2013) were used to detect $T$. intermedium chromatin in WE99. The results demonstrated that the SSR marker Wmc382 located on chromosome arm 2BS amplified a 175-bp band that was specific for T. intermedium chromatin in WE99 (Fig. 2). This indicated that,
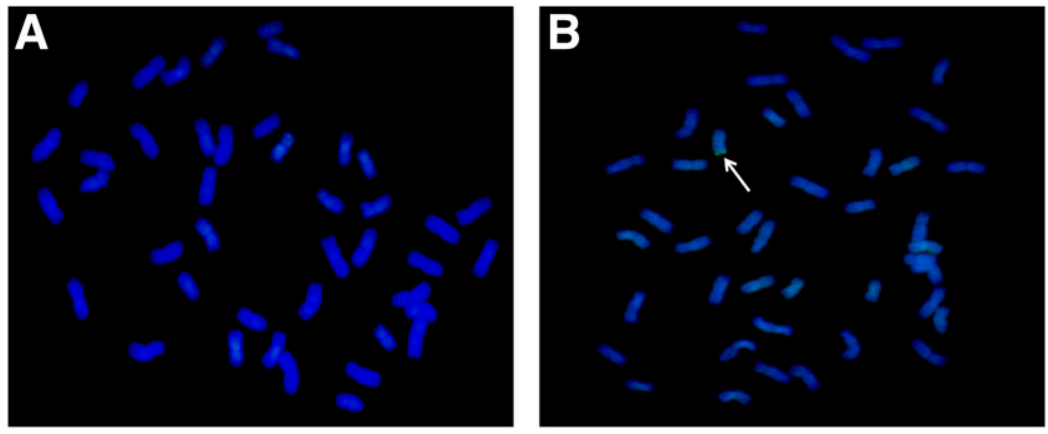

Fig. 1. Genomic in situ hybridization (GISH) detection of the wheat-Thinopyrum intermedium introgression line WE99 using T. intermedium genomic DNA as a probe A, clearly showed 42 wheat chromosomes counterstained with 4,6-diamidino-2-phenylindole (DAPI) and no bright green hybridization signals representing T. intermedium chromatin. B, GISH pattern of a small alien segment translocation with detectable bright green hybridization signals was a positive control. Arrows indicate alien chromatin. 
although $T$. intermedium chromatin was cytologically undetectable, WE99 indeed has a small T. intermedium introgression which may have high homology with some regions of chromosome arm 2BS (Fig. 2). Therefore, WE99 was proved to be a wheat- $T$. intermedium introgression line. Different progenies in five consecutive generations of selfing were also investigated by molecular cytological and agronomical observation. WE99 was genetically and agronomically stable, demonstrating that WE99 was a stable wheat- $T$. intermedium introgression line.

To investigate the relationship between the powdery mildew resistance in WE99 and the $T$. intermedium chromatin detected by the marker Wmc382, several homozygous resistant and susceptible $\mathrm{F}_{2: 3}$ families crossed by Huixianhong and WE99 were screened with the molecular marker $W m c 382$. The result indicated that not all of the resistant $\mathrm{F}_{2: 3}$ families had a $T$. intermedium segment and it was present in some of the susceptible $\mathrm{F}_{2: 3}$ families (Fig. 2). Therefore, the powdery mildew resistance was not contributed by the $T$. intermedium chromatin detected by the marker Wmc382.

Evaluation of powdery mildew resistance and its inheritance in WE99. At the adult plant stage, WE99 was highly resistant to the mixture of $B g t$ isolates collected from northern China in five consecutive wheat growing seasons. At the seedling stage, WE99 showed resistance to 47 of 49 tested $\mathrm{Bgt}$ isolates collected from different regions of China (Fig. 3). In contrast, several resistant commercial cultivars that are currently popular in China, which included Jimai 22, Liangxing 66, Liangxing 99, and Wennong 14, each had a relatively narrower resistant spectrum. Therefore, WE99 had more effective resistance to wheat powdery mildew compared with several resistant commercial cultivars that are widely grown in China.

To investigate the inheritance of the seedling resistance to powdery mildew, Bgt isolate B03, which is the dominant race in North China, was selected to inoculate WE99, Huixianhong, and their derived $\mathrm{F}_{2: 3}$ families. The results demonstrated that WE99 was highly resistant, with an IT 0, while the susceptible parent Huixianhong was highly susceptible, with an IT 4 . The $\mathrm{F}_{1}$ hybrids from the cross of Huixianhong to WE99 were susceptible, with IT 3 to 4, indicating the recessive characteristics of the powdery mildew resistance in WE99. The $F_{2}$ populations of Huixianhong $\times$ WE99 segregated 75 resistant to 120 susceptible plants. The resistance segregation did not produce a good fit of the Mendelian ratio for one recessive resistance gene $\left(\chi_{1: 3}^{2}=18.85, \mathrm{df}=1, P=1.40\right)$ but it seemed to fit the Mendelian ratio of two recessive resistance genes $\left(\chi_{7: 9}^{2}=2.22\right.$, $\mathrm{df}=1, P=0.14)$. Then, $\mathrm{F}_{2}$ populations were transplanted to the field, and 184 plants survived to produce $\mathrm{F}_{3}$ seed. In all, 40 plants of each $\mathrm{F}_{2: 3}$ family were tested for their powdery mildew response to the Bgt isolate B03, and they segregated as 72 homozygous resistant, 97 segregating, and 15 homozygous susceptible, also fitting Mendelian ratio for two recessive resistance genes $\left(\chi^{2} 7: 8: 1=2.23\right.$, df $=2, P=0.33)$.

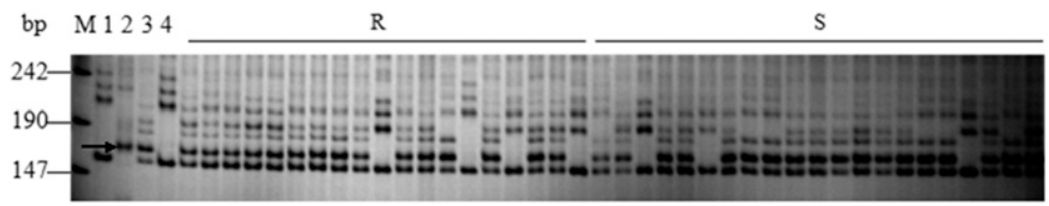

Fig. 2. Molecular detection of the wheat-Thinopyrum intermedium introgression line WE99 using a simple-sequence repeat marker specific for $T$. intermedium genome and amplification of several resistant and susceptible $F_{2}$ plants crossed by Huixianhong and WE99. Lane M, pUC18 Mspl; lane 1, Chinese Spring; lane 2, T. intermedium; lane 3 , WE99; lane 4, Huixianhong; $R=$ resistant and $S=$ susceptible $F_{2}$ plants.

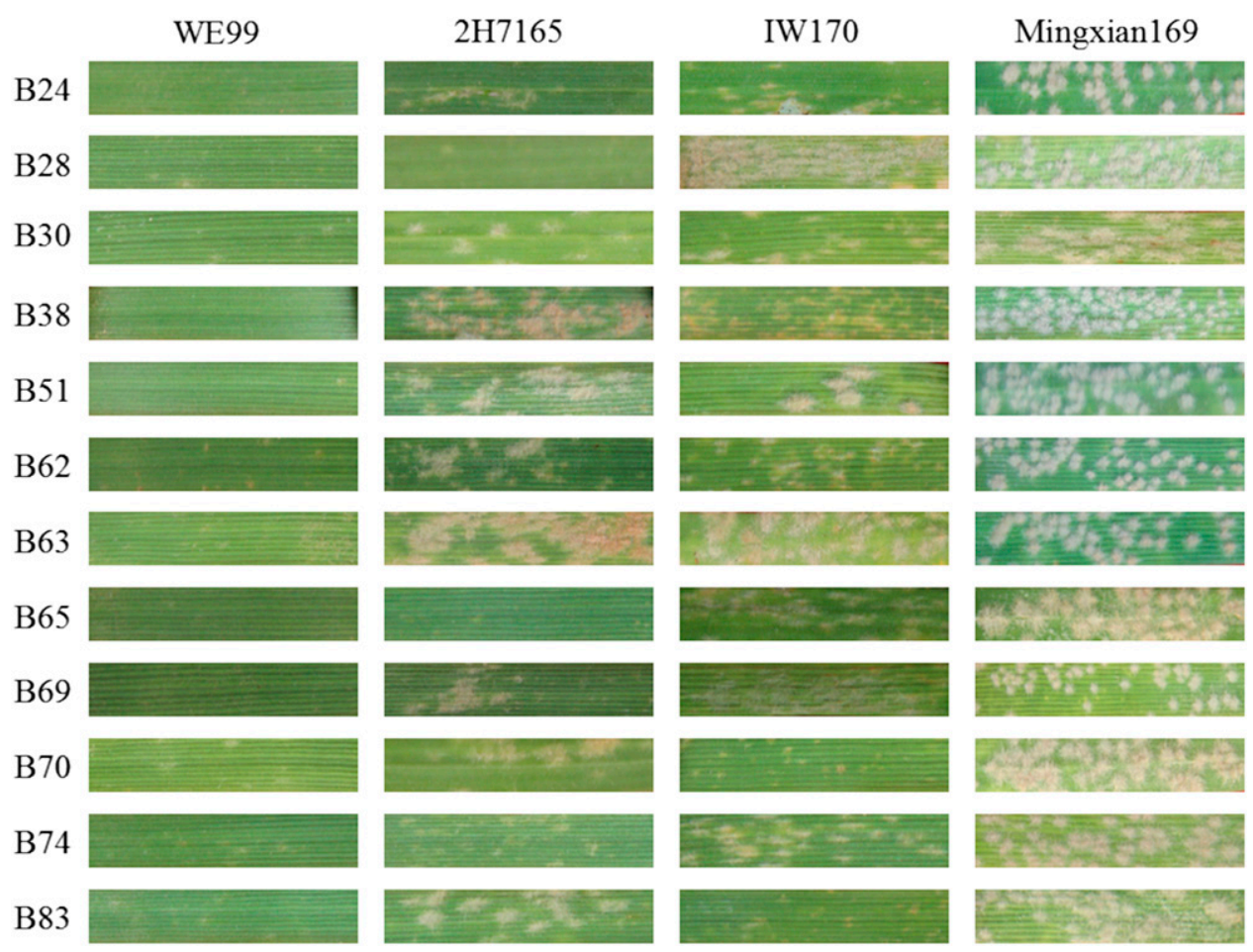

Fig. 3. Reactions of WE99 and the wheat lines $2 \mathrm{H} 7165$ with Pm42 and P170 with MIIW170 to several selected Blumeria graminis f. sp. tritici (Bgt) isolates selected from the 49 Bgt isolates in this study. Mingxian 169 wheat was used as the susceptible control. 
When two independent recessive genes segregate in a Mendelian ratio, about half of the $\mathrm{F}_{2: 3}$ families with phenotype segregation would have one-quarter of plants with the recessive phenotype, and the other half would follow the segregation ratio of two recessive resistance genes that fit a ratio of 7:9 resistant/susceptible plants. However, the results indicated that, within each of the $97 \mathrm{~F}_{2: 3}$ families with segregating phenotypes, there were no $\mathrm{F}_{2: 3}$ families in which one-quarter of plants had a recessive phenotype, and nearly all of the $97 \mathrm{~F}_{2: 3}$ families with phenotype segregation followed the segregation ratio of two recessive resistance genes. Therefore, it was speculated that abnormal segregation might exist within the population and the conclusion of two independent recessive genes segregation might not be correct.

Molecular mapping of the powdery mildew resistance gene in WE99. After screening 400 SSR markers distributed on all 21 wheat chromosomes, 12 markers (Wmc17, Wmc182, Wmc257, Wmc317, Wmc382, Barc55, Barc121, Gwm410, Gwm148, Gwm271, Gwm501, and $C f d 70$ ) showed polymorphism between two parents and the resistant and susceptible bulks (Fig. 4). These resulting markers were then used to genotype the $184 \mathrm{~F}_{2: 3}$ families of Huixianhong and WE99. Only three markers (Gwm148, Gwm271, and Barc55) distributed on chromosome arm 2BS were linked to the powdery mildew resistance in WE99 at genetic distances of 10.4, 11.1, and 13.5 centimorgans (cM), respectively (Fig. 5). Thus, it was concluded that a single recessive gene on chromosome arm $2 \mathrm{BS}$ contributed to the powdery mildew resistance in WE99. This gene was temporarily designated PmWE99. The loci order of PmWE99 and the linked markers was PmWE99-Xgwm148-Xgwm271-Xbarc55 (Fig. 5).

Comparison of $P \boldsymbol{m W E} 99$ and documented $\boldsymbol{P m}$ genes on chromosome arm 2BS. In order to compare PmWE99 with the documented Pm genes on chromosome arm 2BS, 49 B. graminis f. sp. tritici isolates were used to test the reaction patterns of WE99 and two resistance stocks $2 \mathrm{H} 7165$ and P170 with the documented Pm genes Pm42 and MlIW170, respectively, on chromosome arm 2BS. The results demonstrated that WE99 was resistant to 47 of 49 isolates tested, with an avirulence frequency of $95.9 \%$, whereas $2 \mathrm{H} 7165$ and P170 only showed resistance to 38 and 33 of the 49 isolates tested, with lower avirulence frequencies of only 77.6 and $67.3 \%$, respectively (Fig. 3). Therefore, WE99 has a significantly different resistant spectrum from the documented resistance stocks $2 \mathrm{H} 7165$ and P170 with $P m 42$ and MlIW170, respectively.

Segregation distortion detection of PmWE99. From the mapping result, it appears that there was a single recessive gene in WE99; however, the segregation ratio of the resistant phenotypes in the $F_{2}$ and their derived $F_{2: 3}$ families showed abnormal segregation. To clarify this issue, a number of plants corresponding to each genotype at $P m W E 99$ and the linked marker loci in the $\mathrm{F}_{2: 3}$ families were examined. The results showed that the genotype proportions of all the loci fit neither a 3:1 ratio for the single dominant markers Gwm148 and Barc55 nor a 1:2:1 ratio for codominant marker Gwm271 (Table 1), which segregated abnormally. These results were consistent with the occurrence of segregation distortion of the phenotypes in the $\mathrm{F}_{2}$ population and the $\mathrm{F}_{2: 3}$ families.

Further investigation revealed that marker loci that were closer to the centromere of chromosome 2BS showed more segregation distortion, including the locus of PmWE99; and, meanwhile, more genotypes of WE99 appeared closer to the centromere on chromosome 2BS (Table 1; Fig. 5). This result indicated that there may be a genetic variation in the interval between loci PmWE99 and Xbarc55 close to the centromere of chromosome 2BS in WE99, which strongly favored the transmission of gametes with the WE99 allele and, thus, caused abnormal segregation of PmWE99 and its linked markers.

To clarify whether this abnormal segregation also existed at other loci in the $\mathrm{F}_{2: 3}$ families of WE99 and Huixianhong, some other marker loci (i.e., Xwmc17, Xwmc182, Xwmc317, Xbarc121-1, Xbarc121-2, Xcfd70, and Xgwm410) showing polymorphisms between two parents but not linked to PmWE99 were examined for their segregation patterns (Table 1). Unlike PmWE99 and its linked markers, the genotypic proportions at these loci in this population
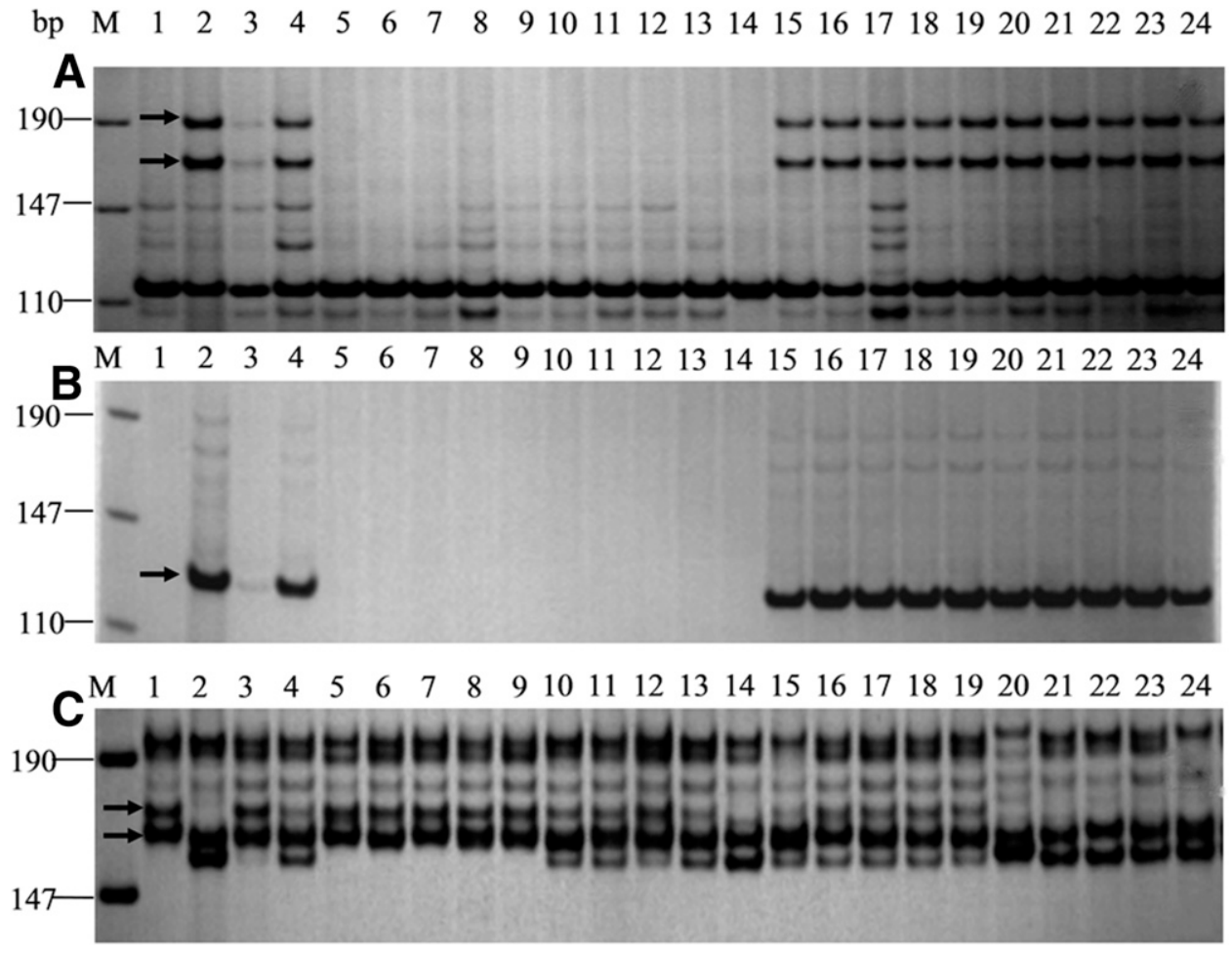

Fig. 4. Examples of amplification patterns of PmWE99-linked markers A, Gwm148; B, Barc55; and C, Gwm271, which were detected in 8\% nondenatured polyacrylamide gels. Arrows indicate the polymorphic bands. Lane 1, WE99; lane 2, Huixianhong; lane 3, resistant bulked pool; lane 4, susceptible bulked pool; lanes 5 to 14 (A and B), homozygous resistant families; lanes 15 to 24 (A and B), segregating or homozygous susceptible families; lanes 5 to 9 (C), homozygous resistant families; lanes 10 to 19 (C), segregating families; and lanes 20 to $24(\mathrm{C})$, homozygous susceptible families. 
all fit a 1:2:1 ratio perfectly. Therefore, the abnormal segregation only existed at the PmWE99 interval and was not common for all the loci in this population.

\section{Discussion}

In this study, the wheat line WE99 crossed by common wheat and T. intermedium showed a high level of resistance to powdery mildew. Compared with several popular resistant commercial cultivars currently in China, it showed a broader resistance spectrum against 49 B. graminis f. sp. tritici isolates collected from different regions of China, indicating that it was a valuable resistance resource for wheat improvement. Using molecular marker detection, WE99 was proven to be a wheat- $T$. intermedium introgression line.

Using BSA and molecular markers, a recessive $P m$ gene, designated PmWE99, was detected on chromosome arm 2BS in WE99. Four documented $\mathrm{Pm}$ genes on chromosome arm 2BS have been identified, including Pm26 that cosegregated with the restricted fragment length polymorphisms (RFLP) marker Wg516 (Rong et al. 2000), Pm42 that cosegregated with RFLP-derived sequence tagged site (STS) marker BF146221 (Hua et al. 2009), MlIW170 that cosegregated with the RFLP-derived STS marker Cau516 (Liu et al. 2012), and Ml5323 flanked by molecular markers Cau516 and CA695634 (Piarulli et al. 2012). These documented Pm genes all followed standard Mendelian inheritance whereas, in contrast, PmWE99 segregated abnormally. PmWE99 was located on the wheat chromosome bin 2BS-0.53-0.75, based on previously reported maps (Hua et al. 2009; Somers et al. 2004), while resistance genes Pm26, MlIW170, and Ml5323 were all located on 2BS-0.84-1.00. Both MlIW170 and $M l 5323$ were dominant genes, yet $P m W E 99$ was recessive. Therefore, PmWE99 is different from Pm26, MlIW170, and Ml5223 according to their genetic model, physical locations, and genetic characteristics. Interestingly, $P m 42$ was only $3.7 \mathrm{cM}$ from $P m W E 99$, and they are both recessive genes (Hua et al. 2009; Somers et al. 2004). To distinguish PmWE99 and Pm42, $49 \mathrm{Bgt}$ isolates were used to test their reaction patterns to powdery mildew. The results indicated that $P m W E 99$ showed a significantly broader resistance spectrum than Pm42. Therefore, PmWE99 also was different from Pm42, and appears to be a new $P m$ gene on chromosome arm 2BS. The allelic relationship between PmWE99 and Pm42 still needs to be determined in the future.

Segregation distortion is a phenomenon in plants, and the reasons are diverse. In wheat, inversion, alien translocation, and gametocidal genes could be several of the causes for the deviated segregation. For example, there was evidence that the homeologous group 2 chromosomes of Triticeae spp. carry genes favoring the transmission of specific gametes (Tsujimoto and Tsunewaki 1988). Fu et al. (2013)

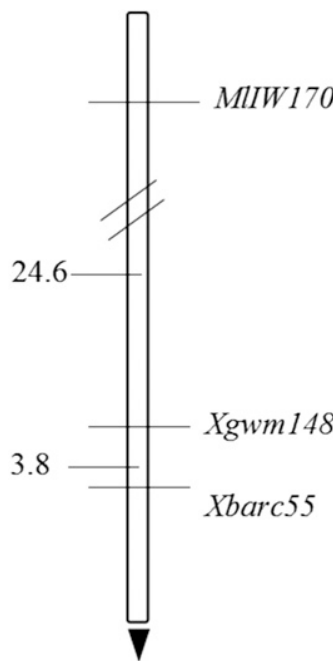

Liu et al. 2012

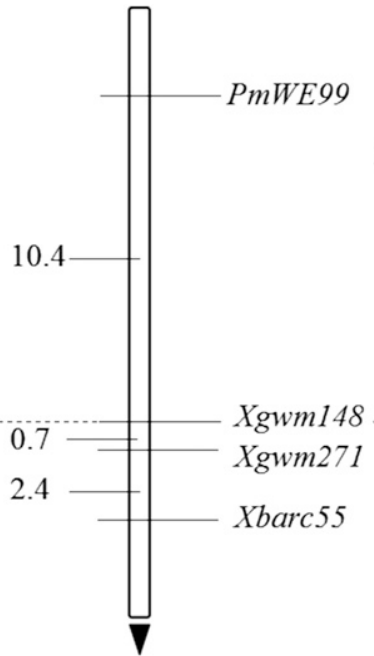

Hua et al. 2012

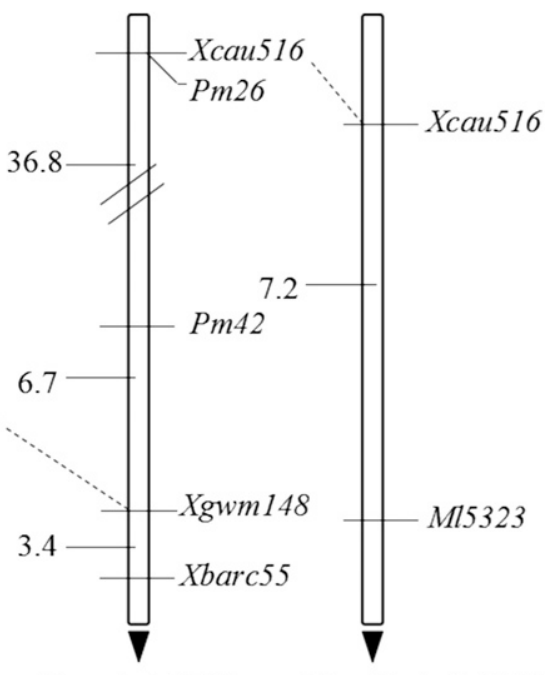

Piarulli et al. 2012

Fig. 5. Linkage map of PmWE99 and its loci comparison with the known Pm genes on chromosome arm 2BS using the anchoring marker loci of Xgwm148 and Xcau516. Genetic distances are shown on the left in centimorgans. The black arrow points to the centromere.

Table 1. Plant numbers for each genotype at PmWE99, its linked marker loci, and some unlinked marker loci with polymorphisms between WE99 and Huixianhong in the $\mathrm{F}_{2: 3}$ families crossed by Huixianhong and WE99 and the $\chi^{2}$ test against the expected Mendelian ratios

\begin{tabular}{|c|c|c|c|c|c|c|c|}
\hline \multirow[b]{2}{*}{ Marker loci } & \multicolumn{4}{|c|}{ Number of each genotype $^{a}$} & \multirow[b]{2}{*}{ Expected ratio } & \multirow[b]{2}{*}{$\chi^{2}$ Value $^{b}$} & \multirow[b]{2}{*}{ Relationship ${ }^{c}$} \\
\hline & $\mathbf{A A}$ & $\mathbf{A B}$ & BB & $\mathbf{A} \mathbf{A}_{-} \mathbf{B}_{-}$ & & & \\
\hline PmWE99 & 69 & 91 & 14 & $\ldots$ & $1: 2: 1$ & 81.78 & Linked \\
\hline Xgwm148 & 80 & $\ldots$ & $\ldots$ & 94 & $1: 3$ & 41.48 & Linked \\
\hline Xgwm271 & 85 & 78 & 11 & $\ldots$ & $1: 2: 1$ & 64.01 & Linked \\
\hline Xbarc55 & 89 & $\ldots$ & $\ldots$ & 85 & $1: 3$ & 66.11 & Linked \\
\hline Xwmc17 & 58 & 41 & 83 & $\ldots$ & $1: 2: 1$ & 4.58 & Unlinked \\
\hline Xwmc182 & 45 & 50 & 83 & $\ldots$ & $1: 2: 1$ & 1.09 & Unlinked \\
\hline Xwmc317 & 57 & 40 & 86 & $\ldots$ & $1: 2: 1$ & 3.82 & Unlinked \\
\hline Xbarc121-1 & 50 & 49 & 83 & $\ldots$ & $1: 2: 1$ & 1.42 & Unlinked \\
\hline Xbarc121-2 & 40 & 47 & 95 & $\ldots$ & $1: 2: 1$ & 0.89 & Unlinked \\
\hline Xcfd70 & 43 & 44 & 83 & $\ldots$ & $1: 2: 1$ & 0.10 & Unlinked \\
\hline Xgwm410 & 47 & 47 & 79 & $\ldots$ & $1: 2: 1$ & 1.30 & Unlinked \\
\hline
\end{tabular}

${ }^{\mathrm{a}} \mathrm{A}=$ WE99 allele, $\mathrm{B}=$ Huixianhong allele, $\mathrm{A}_{-}=$the WE99 allele is dominant and the number includes both the WE99 genotype and the heterozygous genotype, and $\mathrm{B}_{-}=$the Huixianhong allele is dominant and the number includes both the Huixianhong genotype and the heterozygous genotype.

${ }^{\mathrm{b}}$ Values; $\chi^{2}{ }_{0.05,1}=3.84$ and $\chi^{2}{ }_{0.05,2}=5.99 ; P=0.01$.

${ }^{c}$ Linkage relationship with PmWE99. 
reported a recessive $P m$ gene $(p m X)$ located on chromosome arm $2 \mathrm{AL}$ that showed abnormal segregation. The speculation was that there was a genetic variation linked to $p m X$ favoring the transmission of gametes carrying it, similar to PmWE99 in this study. Inheritances of the two stripe rust resistance genes $\mathrm{Sr} 36$ and $\mathrm{Sr} 40$ showed segregation distortion and recombination suppression which involved alien translocations (Tsilo et al. 2008; Wu et al. 2009). In this study, molecular genetic analysis of $\mathrm{F}_{2}$ populations and their derived $\mathrm{F}_{2: 3}$ families from the cross of Huixianhong $\times$ WE99 demonstrated that WE99 carries a recessive gene for powdery mildew resistance. However, phenotype segregation of both $\mathrm{F}_{2}$ populations and their derived $\mathrm{F}_{2: 3}$ families deviated significantly from single recessive gene inheritance. Further investigation of the variation pattern for the number of plants with the WE99 genotype at the loci along the PmWE99 linkage map demonstrated that genetic variation in the PmWE99 linkage map interval that favored the transmission of gametes carrying PmWE99 may have resulted in a deviated segregation ratio. Further studies should be done to make clear the PmWE99-linked genetic variation that caused the segregation distortion. One case to note was that the $T$. intermedium chromatin detected by $W m c 382$ was also introgressed into chromosome arm 2BS. This may not be a coincidence, implying the possibility that this $T$. intermedium introgression may result in a deviated segregation of powdery mildew resistance in WE99.

\section{Acknowledgments}

This research was financially supported by the Chinese Academy of Sciences number XDA08030107, the National Natural Science Foundation of China number 31171550, the National Scientific and Technological Supporting Program of China number 2013BAD01B02, and China Postdoctoral Science Foundation number 2015M570173.

\section{Literature Cited}

An, D. G., Zheng, Q., Zhou, Y. L., Ma, P. T., Lv, Z. L., Li, L. H., Li, B., Luo, Q. L., Xu, H. X., and Xu, Y. F. 2013. Molecular cytogenetic characterization of a new wheat-rye $4 \mathrm{R}$ chromosome translocation line resistant to powdery mildew. Chromosome Res. 21:419-432.

Chen, P. D., Qi, L. L., Zhou, B., Zhang, S. Z., and Liu, D. J. 1995. Development and molecular cytogenetic analysis of wheat-Haynaldia villosa 6VS/6AL translocation lines specifying resistance to powdery mildew. Theor. Appl. Genet. 91:1125-1128.

Chen, X. M. 2005. Epidemiology and control of stripe rust [Puccinia striiformis f. sp. tritici] on wheat. Can. J. Plant Pathol. 27:314-337.

Friebe, B., Heun, M., Tuleen, N., Zeller, F. J., and Gill, B. S. 1994. Cytogenetically monitored transfer of powdery mildew resistance from rye into wheat. Crop Sci. 34:621-625.

Friebe, B., Jiang, J., Raupp, W. J., McIntosh, R. A., and Gill, B. S. 1996. Characterization of wheat alien translocations conferring resistance to diseases and pests current status. Euphytica 91:59-87.

Fu, B. S., Chen, Y., Li, N., Ma, H. Q., Kong, Z. X., Zhang, L. X., Jia, H. Y., and Ma, Z. Q. 2013. pmX: A recessive powdery mildew resistance gene at the $P m 4$ locus identified in wheat landrace Xiaohongpi. Theor. Appl. Genet. 126: 913-921.

Gupta, P. K., Langridge, P., and Mir, R. R. 2010. Marker-assisted wheat breeding: Present status and future possibilities. Mol. Breed. 26:145-161.

Han, F. P., Gao, Z., and Birchler, J. A. 2009. Centromere inactivation and reactivation reveals both epigenetic and genetic components for centromere specification. Plant Cell 21:1929-1939.

Han, F. P., Lamb, J. C., and Birchler, J. A. 2006. High frequency of centromere inactivation resulting in stable dicentric chromosomes of maize. Proc. Natl. Acad. Sci. USA 103:3238-3243.

Han, F. P., Lamb, J. C., Yu, W., Gao, Z., and Birchler, J. A. 2007. Centromere function and nondisjunction are independent components of the maize B chromosome accumulation mechanism. Plant Cell 19:524-533.

Hao, Y. F., Parks, R., Cowger, C., Chen, Z. B., Wang, Y. Y., Bland, D., Murphy, J. P., Guedira, M., Brown-Guedira, G., and Johnson, J. 2015. Molecular characterization of a new powdery mildew resistance gene Pm54 in soft red winter wheat. Theor. Appl. Genet. 128:465-476.

Hardwick, N. V., Jenkins, J. E. E., Collins, B., and Groves, S. J. 1994. Powdery mildew (Erysiphe graminis) on winter wheat: Control with fungicides and the effects on yield. Crop Prot. 13:93-98.

He, R. L., Chang, Z. J., Yang, Z. J., Yuan, Z. Y., Zhan, H. X., Zhang, X. J., and Liu, J. X. 2009. Inheritance and mapping of powdery mildew resistance gene $P m 43$ introgressed from Thinopyrum intermedium into wheat. Theor. Appl. Genet. 118:1173-1180

Herrera-Foessel, S. A., Singh, R. P., Lillemo, M., Huerta-Espino, J., Bhavani, S., Singh, S., Lan, C. X., Calvo-Salazar, V., and Lagudah, E. S. 2014. Lr67/Yr46 confers adult plant resistance to stem rust and powdery mildew in wheat. Theor. Appl. Genet. 127:781-789.

Heun, M., Friebe, B., and Bushuk, W. 1990. Chromosomal location of the powdery mildew resistance gene of Amigo wheat. Phytopathology 80: 1129-1133.

Horst, R. K. 2013. Powdery mildews. Pages 285-293 in: Westcott's Plant Disease Handbook. Springer, Dordrecht, The Netherlands.

Hsam, S. L. K., Huang, X. Q., and Zeller, F. J. 2001. Chromosomal location of genes for resistance to powdery mildew in common wheat (Triticum aestivum L. em Thell.) 6. Alleles at the Pm5 locus. Theor. Appl. Genet. 102:127-133.

Hsam, S. L. K., and Zeller, F. J. 1997. Evidence of allelism between genes Pm8 and $\mathrm{Pm} 17$ and chromosomal location of powdery mildew and leaf rust resistance genes in the common wheat cultivar 'Amigo'. Plant Breed. 116: 119-122.

Hua, W., Liu, Z. J., Zhu, J., Xie, C. J., Yang, T., Zhou, Y. L., Duan, X. Y., Sun, Q. X., and Liu, Z. Y. 2009. Identification and genetic mapping of pm42, a new recessive wheat powdery mildew resistance gene derived from wild emmer (Triticum turgidum var. dicoccoides). Theor. Appl. Genet. 119: 223-230.

Huang, X. Q., Wang, L. X., Xu, M. X., and Roder, M. S. 2003. Microsatellite mapping of the powdery mildew resistance gene Pm5e in common wheat (Triticum aestivum L.). Theor. Appl. Genet. 106:858-865.

Karsai, I., Vida, G., Petrovics, S., Petcu, E., Kobiljski, B., Ivanovska, S., Bedö, Z., and Veisz, O. 2012. Assessment of the spatial genotypic and phenotypic diversity present in the various winter wheat breeding programs in Southeast Europe. Euphytica 186:139-151.

Khan, M. I., Khan, M. A., Ma, H., Khattak, G. S. S., Khan, A. J. , and Mhhammad, T. 2011. Selection of parents for crossing based on genotyping and phenotyping for stripe rust (Puccinia striiformis) resistance and agronomic traits in bread wheat breeding. Cytol. Genet. 45:379-394.

Kosambi, D. D. 1943. The estimation of map distance from recombination values. Ann. Eugen. 12:172-175.

Lillemo, M., Asalf, B., Singh, R. P., Huerta-Espino, J., Chen, X. M., He, Z. H., and Bjørnstad, А. 2008. The adult plant rust resistance loci Lr34/Yr18 and Lr46/Yr29 are important determinants of partial resistance to powdery mildew in bread wheat line Saar. Theor. Appl. Genet. 116:1155-1166.

Lincoln, S., Daly, M., and Lander, E. 1992. Constructing Genetic Maps with Mapmaker/EXP30. Whitehead Institute Technical Report, 3rd ed. Whitehead Institute, Cambridge, MA.

Liu, Z. G., Wang, C. Y., Chen, C. H., and Ji, W. Q. 2013. Cytologic and SSR identification of derivatives from wheat-Thinopyrum intermedium. J. Triticeae Crops 33:1-5.

Liu, Z. J., Zhu, J., Cui, Y., Liang, Y., Wu, H. B., Song, W., Liu, Q., Yang, T. M., Sun, Q. X., and Liu, Z. Y. 2012. Identification and comparative mapping of a powdery mildew resistance gene derived from wild emmer (Triticum turgidum var. dicoccoides) on chromosome 2BS. Theor. Appl. Genet. 124: 1041-1049.

Luo, P. G., Luo, H. Y., Chang, Z. J., Zhang, H. Y., Zhang, M., and Ren, Z. L. 2009 Characterization and chromosomal location of Pm40 in common wheat: A new gene for resistance to powdery mildew derived from Elytrigia intermedium. Theor. Appl. Genet. 118:1059-1064.

Ma, P. T., Xu, H. X., Xu, Y. F., Li, L. H., Qie, Y. M., Luo, Q. L., Zhang, X. T., Li, X. Q., Zhou, Y. L., and An, D. G. 2015a. Molecular mapping of a new powdery mildew resistance gene $P m 2 b$ in Chinese breeding line KM2939. Theor. Appl. Genet. 128:613-622.

Ma, P. T., Zhang, H. X., Xu, H. X., Xu, Y. F., Cao, Y. W., Zhang, X. T., and An, D. G. 2015 b. The gene $P m Y B$ confers broad-spectrum powdery mildew resistance in the multi-allelic $P m 2$ chromosome region of the Chinese wheat cultivar YingBo 700. Mol. Breed. 35:124.

McIntosh, R. A., Dubcovsky, J., Rogers, W. J., Morris, C., Appels, R., and Xia, X. C. 2014. Catalogue of gene symbols for wheat: 2013-2014 supplement. Online publication. http://shigen.nig.ac.jp/wheat/komugi/genes/macgene/supplement 2013 . pdf

Morgounov, A., Tufan, H. A., Sharma, R., Akin, B., Bagci, A., Braun, H. J., Kaya, Y., Keser, M., Payne, T. S., Sonder, K., and McIntosh, R. 2012. Global incidence of wheat rusts and powdery mildew during 1969-2010 and durability of resistance of winter wheat variety Bezostaya 1. Eur. J. Plant Pathol. 132:323-340.

Petersen, S., Lyerly, J. H., Worthington, M. L., Parks, W. R., Cowger, C. Marshall, D. S., Brown-Guedira, G., and Murphy, J. P. 2014. Mapping of powdery mildew resistance gene Pm53 introgressed from Aegilops speltoides into soft red winter wheat. Theor. Appl. Genet. 128:303-312.

Piarulli, L., Gadaleta, A., Mangini, G., Signorile, M. A., Pasquini, M., Blanco, A., and Simeone, R. 2012. Molecular identification of a new powdery mildew resistance gene on chromosome $2 \mathrm{BS}$ from Triticum turgidum ssp. dicoccum. Plant Sci. 196:101-106.

Rong, J. K., Millet, E., Manisterski, J., and Feldman, M. 2000. A new powdery mildew resistance gene: Introgression from wild emmer into common wheat and RFLP-based mapping. Euphytica 115:121-126.

Schneider, D. M., Heun, M., and Fischbeck, G. 1991. Inheritance of the powdery mildew resistance gene $P m 9$ in relation to $P m 1$ and $P m 2$ of wheat. Plant Breed. 107:161-164. 
Sharma, A. K., Sharma, R. K., and Babu, K. S. 2004. Effect of planting options and irrigation schedule on development of powdery mildew and yield of wheat in the north western plains of India. Crop Prot. 23:249-253.

Sharp, P. J., Kreis, M., Shewry, P. R., and Gale, M. D. 1988. Location of $\beta$-amylase sequences in wheat and its relatives. Theor. Appl. Genet. 75:286-290.

Si, Q. M., Zhang, X. X., Duan, X. Y., Sheng, B. Q., and Zhou, Y. L. 1992. On gene analysis and classification of powdery mildew (Erysiphe graminis f. sp. tritici) resistant wheat varieties. Acta Phytopathol. Sin. 22:349-355.

Somers, D. J., Isaac, P., and Edwards, K. 2004. A high-density microsatellite consensus map for bread wheat (Triticum aestivum L.). Theor. Appl. Genet. 109:1105-1114.

Spielmeyer, W., Singh, R. P., McFadden, H., Wellings, C. R., Huerta-Espino, J., Kong, X., Appels, R., and Lagudah, E. S. 2008. Fine scale genetic and physical mapping using interstitial deletion mutants of Lr34/Yr18: A disease resistance locus effective against multiple pathogens in wheat. Theor. Appl. Genet. 116:481-490.

Sun, X. L., Liu, D., Zhang, H. Q., Huo, N. X., Zhou, R. H., and Jia, J. Z. 2006. Identification and mapping of two new genes conferring resistance to powdery mildew from Aegilops tauschii (Coss.) Schmal. J. Integr. Plant Biol. 48:1204-1209.
Tsilo, T. J., Jin, Y., and Anderson, J. A. 2008. Diagnostic microsatellite markers for the detection of stem rust resistance gene $\mathrm{Sr} 36$ in diverse genetic backgrounds of wheat. Crop Sci. 48:253-261.

Tsujimoto, H., and Tsunewaki, K. 1988. Gametocidal genes in wheat and its relatives III. Chromosome location and effects of two Aegilops speltoidesderived gametocidal genes in common wheat. Genome 30:239-244.

Wu, S., Pumphrey, M. O., and Bai, G. 2009. Molecular mapping of stem rust resistance gene $S r 40$ in wheat. Crop Sci. 49:1681-1686.

Xiao, M. G., Song, F. J., Jiao, J. F., Wang, X. M., Xu, H. X., and Li, H. J. 2013. Identification of the gene Pm47 on chromosome 7BS conferring resistance to powdery mildew in the Chinese wheat landrace Hongyanglazi. Theor. Appl. Genet. 126:1397-1403.

Xu, H. X., Yao, G. Q., Xiong, L., Yang, L. L., Jiang, Y. M., Fu, B. S., Zhao, W. F., Zhang, Z. Q., Zhang, C. Q., and Ma, Z. Q. 2008. Identification and mapping of pm2026: A recessive powdery mildew resistance gene in an einkorn (Triticum monococcum L.) accession. Theor. Appl. Genet. 117:471-477.

Xu, H. X., Yin, D. D., Li, L. H., Wang, Q. X., Li, X. Q., Yang, X. M., Liu, W. H., and An, D. G. 2012. Development and application of EST based markers specific for chromosome arms of rye (Secale cereale L.). Cytogenet. Genome Res. 136:220-228. 